\title{
Symptoms of Anxiety, Depression, and Aggression in Non-clinical Children: Relationships with Self-report and Performance-based Measures of Attention and Effortful Control
}

\author{
Peter Muris · Els van der Pennen · Rianne Sigmond $\cdot$ Birgit Mayer
}

Published online: 30 April 2008

(C) The Author(s) 2008

\begin{abstract}
This study investigated the relation between the regulative trait of effortful control, and in particular attention control, and psychopathological symptoms in a sample of 207 non-clinical children aged 8-12 years. For this purpose, children completed selfreport scales for measuring regulative traits and various types of psychopathological symptoms (i.e., anxiety, depression, and aggression) and were tested with a neuropsychological battery for measuring attention/effortful control capacity. Results indicated that self-report and performance-based measures of attention/effortful control were at best moderately correlated. Further, it was found that self-report indexes of attention/effortful control were clearly negatively related to psychopathological symptoms, which provides support for the notion that low regulation is associated with higher levels of psychopathology. Finally, the performance-based measure of attention/effortful control was not convincingly related to psychopathological symptoms.
\end{abstract}

Keywords Attention control · Effortful control · Psychopathological symptoms · Children

\section{Introduction}

Epidemiological research has shown that a substantial proportion of children and adolescents suffer from psychiatric disorders [1-3]. The most frequently diagnosed disorders can be roughly divided in two categories: internalizing problems (e.g., anxiety disorders, depression) and externalizing problems (e.g., disruptive behavior disorders) [4]. Only a small percentage of the children with problems actually receive services, and so many of these untreated children go on to become adults with psychiatric disorders [5]. During the last decades, clinical psychology researchers have increasingly accepted the notion that many psychiatric problems in adults have their origins during childhood, resulting in an

P. Muris $(\varangle) \cdot$ E. van der Pennen $\cdot$ R. Sigmond · B. Mayer Institute of Psychology, Erasmus University Rotterdam, Burgemeester Oudlaan 50, Suite T13-37, P.O. Box 1738, 3000 DR Rotterdam, The Netherlands e-mail: muris@fsw.eur.nl 
intensification of studies on the etiology of childhood psychiatric disorders [6]. This research has made clear that childhood disorders do not have their origins in a single factor, but originate from the dynamic interplay of multiple factors. Most studies have focused on vulnerability and risk factors such as reactive temperament, negative learning experiences, stressful life events, and adverse family factors, which are all thought to increase children's proneness to develop psychiatric problems and disorders [7-9]. Fortunately, there are also protective influences, which may serve to shield children and adolescents against the development of psychopathological symptoms.

One protective variable that is currently receiving an increasing amount of research attention is effortful control. Briefly, effortful control can best be defined as the ability to inhibit a dominant response to perform a subdominant response, and refers to self-regulative processes that enable a person to control or regulate behavior under certain circumstances [10, 11]. Effortful control is generally thought to consist of two main components: inhibitory control, which pertains to the ability to inhibit one's behavior if necessary, and attention control, which can be defined as the ability to focus and shift attention when needed. It is generally assumed that the capacity for effortful control processes is innate [12]. Relatively few data exist on the temporal stability of this regulative temperament factor, but available evidence has revealed reasonable stability from infancy through preschool and into the early school years [13, 14], and so it can be concluded that effortful control has trait-like qualities [10]. Meanwhile, it is also clear that this regulative factor further develops as a result of brain maturation, especially in the frontal lobes, in interaction with the environment $[15,16]$. The gradual improvement of effortful control increasingly enables children to regulate emotions and to control their behavior, which may have positive effects on their social interactions with other children $[17,18]$. In children who have little effortful control by nature or who fail to adequately develop this regulative trait, such normal processes can be disturbed and this may increase their vulnerability to develop psychopathological symptoms.

Various studies have demonstrated that low levels of effortful control are associated with higher levels of internalizing and externalizing symptoms. For example, in an investigation by Eisenberg and colleagues [19], parents and teachers completed rating scales for measuring effortful control in a sample of 4- to 8-year-old children. Some of these children displayed internalizing or externalizing problems, whereas other children did not manifest any psychological problems. Results showed that children with internalizing problems and children with externalizing problems scored relatively low on effortful control as compared to children without psychological problems. Other studies have yielded comparable results: that is, low levels of effortful control are associated with higher levels of psychopathological symptoms [20-22], although the link with externalizing symptoms generally appeared stronger than that with internalizing symptoms [23-25]. However, the latter finding may be primarily due to the fact that the instruments that have been used in the above-mentioned studies were somewhat biased to the assessment of inhibitory control. Research employing measures that tap aspects of attention control has demonstrated that internalizing problems such as anxiety and depression are also convincingly associated with low levels of effortful control [26-31]. In their recently formulated theory on the role of temperament in the etiology of childhood psychopathology, Muris and Ollendick [32] assume that different aspects of effortful control are allied to specific types of symptoms. More precisely, lack of attention control seems more strongly linked to internalizing symptoms, whereas a deficiency of inhibitory control is more clearly related to externalizing symptoms. Note that these differential relations are in keeping with the clinical observation that internalizing disorders are typically 
characterized by uncontrollable negative thought, while externalizing disorders are frequently marked by impulsive and disinhibited behavior [33].

Research on the psychopathological correlates of effortful control has predominantly relied on self-report scales for measuring this regulative trait. Most studies have employed subscales of temperament questionnaires such as the Child Behavior Questionnaire [34] and the Early Adolescent Temperament Questionnaire [35], or scales that have been derived from these instruments such as the Attention Control Scale (ACS) [36] and the Effortful Control Scale (ECS) [29]. Only a number of investigations have relied on behavioral batteries [13, 37], in spite of the fact that effortful control shows strong resemblance to what neuropsychologists refer to as 'executive functions', which makes that this regulative factor can be readily assessed by means of cognitive performance tests that tap children's capacity of governing their attention and controlling their behavior. This research has generally confirmed the notion that effortful control is especially associated with externalizing problems, although it should again be noted that most performance tests mainly focus on the control of behavior (inhibitory control) and largely neglect the aspect of attention control. Interestingly, Manly and colleagues [38, 39] have developed the Test of Everyday Attention for Children (TEA-Ch), which primarily focuses on attention processes and includes various tasks that call on focusing, sustaining, and switching attention.

The current study further examines the link between the regulative trait of effortful control, and in particular attention control, and psychopathological symptoms in children. For this purpose, a large sample of non-clinical children aged 8 to 12 years were tested with the TEA-Ch and completed self-report scales for measuring attention control (ACS) and effortful control (ECS) as well as symptoms of anxiety, depression, and aggression. In this way, we investigated (1) the relationships between TEA-Ch scores and self-report indices of attention control and effortful control, and (2) the links between attention control and effortful control as measured by the TEA-Ch and self-report questionnaires, on the one hand, and psychopathological symptoms in children, on the other hand. It was anticipated that behavioral (TEA-Ch) and self-report (ACS and ECS) indices of attention and effortful control would be positively related. Further, we expected to find negative associations between indices of attention and effortful control (TEA-Ch, ACS, and ECS) and measures of anxiety, depression, and aggression, which of course would provide further support for the notion that these types of psychopathological symptoms are accompanied by lower levels of this regulative trait.

\section{Method}

Participants

A total of 207 children (90 boys and 117 girls) of three primary schools in the Rotterdam region of the Netherlands were recruited for the purpose of the present study. Children had a mean age of 10.25 years $(\mathrm{SD}=1.02$; range $8-12$ years). Participants' parents were approached by mail. In the letter, parents received information about the study and they were asked to give consent for their child's participation. Of the children who were initially invited, about $65 \%$ was allowed to participate in the study. No exact information on the socio-economic background of the children was available, but it can be mentioned that the majority (i.e., 83.1\%) was from original Dutch descent. The other $16.9 \%$ had an ethnic minority background (e.g., Surinam, Antillean, Turkish, and Moroccan), which in the Netherlands is usually indicative for a lower socio-economic status. 
Assessment

\section{Questionnaires}

The child version of the Attention Control Scale (ACS) [36] is a 20-item self-report questionnaire measuring the ability to focus and shift attention if necessary (e.g., "When concentrating, I do not notice what happens around me", "I can easily write or read, while I am talking on the phone"). Items have to be scored on a 4-point scale with $0=$ never, $1=$ sometimes, $2=$ often, and $3=$ always. After recoding inversely formulated items, a total score can be computed by summing across relevant items. In all cases, higher scores reflect higher levels of attention control. Relatively little is known about the reliability and validity of the ACS for children. Research has indicated that the total scale is internally consistent (with $\alpha \mathrm{s}$ in the 0.70 range), positively correlated with perceived control $(r=0.22)$ and school performance (with $r$ s between 0.23 and 0.42 ), but negatively with symptoms of Attention-Deficit and Hyperactivity Disorder $(r=-0.50)$ [30, 40]. Furthermore, the parent-child agreement of the ACS also appears satisfactory $(\mathrm{ICC}=0.72$ ) [31].

The Effortful Control Scale (ECS) [29] consists of 15 items that have to be scored on a four-point scale with $1=$ not true, $2=$ somewhat true, $3=$ true, and $4=$ very true. This scale shows considerable overlap with the ACS in that most of the items measure aspects of attention control. However, the ECS also includes a number of items that measure the effortful control component of inhibitory control (e.g., "When someone tells me to stop doing something, it is easy for me to stop"). A total score can be derived by summing scores on individual items (after recoding reversed items), with higher scores being indicative of higher levels of effortful control. Little is known about the psychometric properties of the ECS, but the study by Muris [29] has indicated that the internal consistency of the scale is sufficient $(\alpha=0.73)$.

The Revised Child Anxiety and Depression Scale (RCADS) [41] is an adaptation of the Spence Children's Anxiety Scale [42] and intends to assess symptoms of DSM-defined anxiety disorders and major depressive disorder. The scale consists of 47 items that can be allocated to six subscales: social phobia (9 items; e.g., "I am afraid of looking foolish in front of people"), panic disorder (9 items; e.g., "My heart suddenly beats too quickly for no reason"), major depressive disorder (10 items; e.g., "I feel sad or empty"), separation anxiety disorder (7 items; "I fear being away from my parents"), generalized anxiety disorder (6 items; "I worry that bad things will happen to myself"), and obsessive-compulsive disorder (6 items; "I have to do things just right to stop bad things"). Items have to be scored on a 4-point scale with $0=$ never, $1=$ sometimes, $2=$ often, and $3=$ always. In the current study, two scores were derived from the RCADS: a total anxiety score and a total depression score. Previous research has indicated that the RCADS is reliable in terms of internal consistency and temporal stability, and displays good validity as evidenced by positive associations with concurrent childhood questionnaires of anxiety and depression [41, 43, 44].

The Child Rating of Aggression (CRA) is a self-report version of the Teacher Rating scale for Aggression [45], which consists of 21 items referring to aggressive feelings and behaviors of children: 6 items reflect reactive aggression (e.g., "I get angry for no reason"), 10 items represent proactive aggression (e.g., "I am mean"), whereas 5 items can not be classified in these two categories. Each item has to be scored on a 5-point scale with $1=$ never, $2=$ seldom, $3=$ sometimes, $4=$ often, and $5=$ almost always. In the current study, a total aggression score was computed by summing the scores on all 21 items. There 
is tentative support for the psychometric qualities of the CRA. That is, the scale is reliable in terms of internal consistency, and discriminates well between children with and without teacher-observed behavioral problems [28, 46].

\section{Neuropsychological Test}

The Test of Everyday Attention for Children (TEA-Ch) [38] is a neuropsychological battery that can be employed to index children's ability of attention control. In the current study, five subtests were used: (1) The Sky Search subtest provides an index of selective attention (i.e., the ability to search for relevant information while ignoring irrelevant, distracting information). This subtest consists of an A3-sheet depicting the sky above a city which is full with spaceships that fly in pairs: for 108 of the pairs, the two spaceships are different, but for the 20 target pairs both spaceships are identical. Children are instructed to search for the identical target pairs and to mark them as quickly as possible. The time needed to complete the test and the number of correctly identified target items are recorded, and eventually yield a time-per-target score. This score is corrected for motor speed by administrating a motor control version of the task during which children have to mark pairs of spaceships on a separate A3-sheet that only displays the target items. (2) The Score! subtest measures attention focusing (i.e., the ability to preserve attention and alertness while doing a task that is not implicitly stimulating), and consists of 10 trials during which children have to silently count (i.e., without the assistance of fingers) the number of tones that are produced by the computer. Each trial presents between 9 and 15 identical tones, which are separated by silent inter-stimulus intervals of variable duration (i.e., 500-5,000 ms). At the end of each trial, children report the number of sounds that they have counted. This subtest yields a total score, which indicates the number of correctly counted trials (range 0-10). (3) The Score-Double Task intends to measure children's capacity of divided attention (i.e., the ability to coordinate and plan complex attention tasks). During this subtest, which again consists of 10 trials, children not only have to count the number of tones, but they also have to listen to a news bulletin (also presented by the computer) in which the name of an animal is mentioned. At the end of each trial, children have to report the number of tones they have counted as well as the animal that was mentioned in the bulletin. A total score can be derived by summing the number of correctly counted trials and the number of correctly reported animals (range 0-20). (4) The Walk-Don't Walk subtest assesses children's inhibitory control (i.e., the ability to control and inhibit behavioral responses), which also requires attention resources. As such, this subtest provides an index of inhibitory control as well as attention control. During this subtest, children are given an A4-sheet showing 'paths' that are each made up of 14 squares ("flagstones"). Children have to listen to tones generated by the computer: the computer may present a 'Go' tone, which indicates that the path is safe and that children can move to the next flagstone. Eventually, the computer will generate a 'No-Go' tone, which indicates that the path is no longer safe and the child should not make the next step. Children hold a marker pen approximately $2 \mathrm{~cm}$ above the sheet and are asked to check each step as long as they hear the 'Go' tone, they should not check a stone if they hear the 'No-Go' tone. There are 20 paths for which the tones are presented in an increasing frequency. A total score is obtained by counting the numbers of paths that are correctly checked (range 0-20). (5) The Opposite World subtest essentially measures flexibility of attention shifting (i.e., the ability to shift attention at will). During this test, children are presented with three A-4 sheets, each displaying a randomly ordered string of 
the digits 1 and 2. In the 'Same World' condition, children are asked to read aloud the digits as quickly as possible. In the 'Opposite World' condition, they essentially receive the same instruction, but this time they have to say the opposite for each digit (i.e., "one" for 2, and "two" for 1). Children first start with a Real World sheet in order to prime the prepotent set of naming the numbers, and then have to read two Opposite World sheets. The time needed to read these Opposite World sheets reflects the score on this test.

Raw scores on the TEA-Ch subtests were subjected to a Z-transformation and then recoded in such way that higher scores were indicative for higher levels of attention and effortful control. In this way, it became also possible to compute a total TEA-Ch score in which various aspects of this regulative trait were combined.

Psychometric properties of the TEA-Ch appear satisfactory. Most of the subtests have been found to possess sufficient to good test-retest reliability (with test-retest correlations of various subtests varying between 0.57 and 0.87 ). Furthermore, research has also provided support for the validity of the TEA-Ch, as evidenced by significant correlations with other indexes of attention (e.g., Stroop color naming task) and measures of intelligence and school performance $[38,39]$. In addition, children with Attention-Deficit and Hyperactivity Disorder, who are known for their attention problems, perform significantly worse on this test as compared to other clinically referred youths [47].

\section{Procedure}

After obtaining informed consent from their parents, children first completed the set of questionnaires (ACS, ECS, RCADS, and CRA). This was done in their classrooms in the presence of the teacher and a research assistant who answered questions if necessary. In the month following the completion of questionnaires, children were tested individually with the TEA-Ch by a trained research assistant. This assistant was trained by the first author in the administration of this test, and always blind to children's scores on the questionnaires. The TEA-Ch assessment took place in a private room at children's school and lasted for about 25 min. After this session, children received a small present in return for their participation in the study.

\section{Results}

\section{General Findings}

Before addressing the main research issues of the present study, a number of general remarks are in order. First, the reliability of various questionnaires appeared sufficient to good: that is, Cronbach's alphas varied between 0.66 (ECS) and 0.92 (RCADS Anxiety). Second, a number of significant gender differences emerged. As can be seen in Table 1, girls displayed higher levels of anxiety symptoms $[t(205)=3.17, p<0.01]$, whereas boys exhibited higher levels of aggression $[t(205)=2.61, p=0.01]$. Further, on the ACS, boys reported higher levels of attention control than girls $[t(205)=2.22, p<0.05]$. In contrast, on the Sky Search subtest of the TEA-Ch, girls performed somewhat faster than boys $[t(205)=3.75, p<0.001]$, suggesting that they have better selective attention. Third and finally, significant positive correlations were observed between age and ACS $(r=0.22)$ and various TEA-Ch scores ( $r$ s between 0.20 and 0.35 ), which indicated that with increasing age, children's attention and effortful control improved. On the other hand, small negative correlations emerged between age and symptoms of anxiety and depression 
Table 1 General statistics for various questionnaires and the TEA-Ch: Mean scores, standard deviations, gender differences, internal consistency, and correlations with age

\begin{tabular}{|c|c|c|c|c|c|}
\hline & $\begin{array}{l}\text { Total sample } \\
(N=207)\end{array}$ & $\begin{array}{l}\text { Boys } \\
(n=90)\end{array}$ & $\begin{array}{l}\text { Girls } \\
(n=117)\end{array}$ & $\begin{array}{l}\text { Internal } \\
\text { consistency }\end{array}$ & $\begin{array}{l}r \text { with } \\
\text { age }\end{array}$ \\
\hline $\mathrm{ACS}$ & 31.07 (7.29) & $32.35(7.25)_{\mathrm{a}}$ & $30.09(7.20)_{\mathrm{b}}$ & 0.73 & $0.22 * *$ \\
\hline ECS & $42.00(5.60)$ & $42.22(5.37)_{\mathrm{a}}$ & $41.83(5.78)_{\mathrm{a}}$ & 0.66 & 0.13 \\
\hline RCADS anxiety & $26.15(14.63)$ & $22.56(13.66)_{a}$ & $28.91(14.81)_{\mathrm{b}}$ & 0.92 & $-0.18^{*}$ \\
\hline RCADS depression & $6.84(3.88)$ & $6.41(3.52)_{a}$ & $7.17(4.11)_{\mathrm{a}}$ & 0.75 & $-0.16^{*}$ \\
\hline CRA & $33.14(8.04)$ & $34.78(8.24)_{\mathrm{a}}$ & $31.87(7.69)_{\mathrm{b}}$ & 0.83 & -0.02 \\
\hline \multicolumn{6}{|l|}{ TEA-Ch } \\
\hline Total score ${ }^{\dagger \dagger}$ & $0.00(3.14)$ & $-0.45(3.37)_{\mathrm{a}}$ & $0.34(2.93)_{\mathrm{a}}$ & 0.62 & $0.35^{* *}$ \\
\hline Sky search & $3.45(1.00)$ & $3.74(1.04)_{\mathrm{a}}$ & $3.23(0.91)_{\mathrm{b}}$ & 0.29 & $0.22 * *$ \\
\hline Score! & $8.95(1.13)$ & $8.79(1.24)_{\mathrm{a}}$ & $9.08(1.03)_{\mathrm{a}}$ & 0.28 & $0.20 * *$ \\
\hline Score-double task & $16.26(3.00)$ & $16.18(3.10)_{\mathrm{a}}$ & $16.32(2.93)_{\mathrm{a}}$ & 0.46 & $0.33 * *$ \\
\hline Walk-don't walk & $15.29(2.74)$ & $15.56(2.31)_{\mathrm{a}}$ & $15.09(3.02)_{\mathrm{a}}$ & 0.34 & 0.08 \\
\hline Opposite world & $26.88(5.21)$ & $27.32(6.17)_{\mathrm{a}}$ & $26.53(4.32)_{\mathrm{a}}$ & 0.50 & $0.27 * *$ \\
\hline
\end{tabular}

Note $:$ ACS = Attention Control Scale, ECS = Effortful Control Scale, RCADS = Revised Child Anxiety and Depression Scale, CRA $=$ Child Rating of Aggression, TEA-Ch $=$ Test of Everyday Attention in Children. Means with different subscripts differ at $p<0.01$

$\dagger$ For questionnaires and the TEA-Ch Total score, Cronbach's alphas were computed. For the TEA-Ch subtests, this was not possible and so correlations with the total test score are reported

${ }^{\dagger \dagger}$ For computing the TEA-Ch total score, scores on individual subtests were standardized, recoded in such way that higher scores reflected higher levels of attention/effortful control, and then summed. $* p<0.05$, $* * p<0.01$

( $r$ s being -0.18 and -0.16 , respectively), which means that these symptoms tended to decline as children became older.

\section{Relationships Among Measures of Attention and Effortful Control}

Correlations among various measures of attention and effortful control are displayed in Table 2. Note that the ACS and the ECS were significantly positively correlated $(r=0.67)$, which is of course not that surprising given the fact that both self-report questionnaires index comparable regulative traits (in particular attention control), and even share a number of items with a highly similar content. Associations between self-report questionnaires and scores on the TEA-Ch were not particularly convincing. Only for the ACS, a number of small but significant correlations with the performance-based measure of attention/effortful control emerged. That is, the ACS was significantly correlated with the TEA-Ch total score $(r=0.24)$ as well as with the subtests measuring attention focusing (Score!), divided attention (Score-Double task), and flexibility of attention shifting (Opposite world; $r$ s between 0.17 and 0.21 ). In all cases, correlations were positive, indicating that higher levels of self-reported attention control were associated with better performance on the TEA-Ch.

As there were significant age and gender effects on various measures of attention and effortful control, correlations were also computed while controlling for these demographic variables (i.e., partial correlations). Although some of the correlations attenuated as a result 
Table 2 Correlations among various self-report (ACS, ECS) and performance-based (TEA$\mathrm{Ch})$ measures of attention and effortful control

Note: $N=207$.

$\mathrm{ACS}=$ Attention Control Scale,

$\mathrm{ECS}=$ Effortful Control Scale,

TEA-Ch $=$ Test of Everyday

Attention for Children.

$* p<0.05, * * p<0.01$,

$* * * p<0.001$

\begin{tabular}{lll}
\hline & ACS & ECS \\
\hline ACS & - & $0.67^{* * *}$ \\
ECS & $0.67^{* * *}$ & - \\
TEA-Ch & & \\
$\quad$ Total score & $0.24^{* *}$ & 0.10 \\
Sky search & 0.09 & 0.04 \\
Score! & $0.17^{*}$ & 0.11 \\
Score-double task & $0.21^{* *}$ & 0.10 \\
Walk-don't walk & 0.09 & -0.02 \\
Opposite world & $0.19^{* *}$ & 0.09 \\
\hline
\end{tabular}

of this correction, the pattern of findings essentially remained the same. That is, the correlation between the ACS and ECS remained substantial (partial $r=0.67$ ), whereas for the ACS a number of small but significant links with TEA-Ch performance were observed (partial $r$ s between 0.15 and 0.20 ).

\section{Relations Between Attention/Effortful Control and Psychopathological Symptoms}

The relations between attention/effortful control indexes and scores on scales for measuring psychopathological symptoms are shown in Table 3. As can be seen, self-reported attention and effortful control were negatively related to various types of psychopathological symptoms, although it should be noted that correlations with symptoms of anxiety and depression ( $r$ s between -0.51 and -0.62 ) were clearly more convincing than those with symptoms of aggression ( $r$ s between -0.17 and -0.38 ; all $Z s \geq 2.78, p s<0.01$ ). Correlations between the TEA-Ch and psychopathological symptoms scores were small: the total score of this performance-based attention/effortful control measure was only significantly (negatively) associated with symptoms of anxiety and depression ( $r$ s being -0.15 and -0.16 , respectively).

When controlling for gender and age effects, the correlations between self-reported attention and effortful control and psychopathological symptoms remained substantial (all $r$ s between -0.20 and -0.62 , all $p s<0.01$ ), whereas the links between performance-based attention/effortful control and symptom scores were no longer significant ( $r$ s between 0.03 and $-0.13, p=0.07)$.

Table 3 Correlations and partial correlations between attention/effortful control indexes and scores on scales for measuring symptoms of anxiety, depression, and aggression

\begin{tabular}{lllc}
\hline & Anxiety & Depression & Aggression \\
\hline ACS & $-0.51^{* *}$ & $-0.54^{* *}$ & $-0.17^{*}$ \\
ECS & $-0.62^{* *}$ & $-0.57^{* *}$ & $-0.38^{* *}$ \\
TEA-Ch & $-0.15^{*}$ & $-0.16^{*}$ & 0.01 \\
\hline
\end{tabular}

Note: $N=207$. ACS $=$ Attention Control Scale, ECS $=$ Effortful Control Scale, TEA-Ch $=$ Test of Everyday Attention for Children. $* p<0.05, * * p<0.001$ 


\section{Discussion}

The present study examined the relationships between self-report and performance-based measures of attention and effortful control and psychopathological symptoms in a sample of 8- to 12-year-old non-clinical children. The main results can be catalogued as follows. First of all, correlations between self-reports of attention and effortful control and the TEACh were not convincing. In fact only, the ACS was significantly related to the TEA-Ch total score and various of its subtests. Further, self-reported attention and effortful control (ACS and ECS) were clearly negatively related to psychopathological symptoms. However, the correlations between the TEA-Ch and symptom scores were very small and even non-significant after controlling for demographic variables (i.e., gender and age).

The data indicate that there is little overlap between self-report and performance-based indexes of attention and effortful control. Only the ACS displayed some modest but significant associations with various aspects of attention performance as indexed by the TEA-Ch. The finding that the ACS was a better indicator of TEA-Ch test performance than the ECS was not that surprising given the fact that the ACS and the TEA-Ch are both primarily measures of attention control [36, 38], whereas the ECS attempts to measure attention as well as inhibitory control [29].

A number of explanations for the observation that self-report and performance-based indexes had so little in common can be put forward. First of all, it may well be the case that the psychometric properties of the ACS and ECS are insufficient and hence the scales might be poor indicators of the regulative traits of attention and effortful control. This idea is partly supported by the rather modest reliability coefficients that were found for both scales. It has been noted that this is probably due to a number of reversed items that are included in these scales [48, 49]. While it is clear that such items are incorporated to cancel out response tendencies, several authors have indicated that they might undermine the psychometric properties of a scale and this might be especially true in child populations [50]. Second, it is also possible that the ACS and the ECS do not really assess children's actual levels of attention and effortful control, but rather reflect children's personal beliefs about how well they can control cognitive processes. If true, this would seriously question the validity of these scales. However, there is some evidence showing that self-reported attention control are actually predictive of children's performance in situations that call upon this regulative trait. That is, Muris [40] found that child- and parent-ratings of attention control (as indexed by the ACS) were predictive of teacher-reported school performance. A third possibility is that TEA-Ch scores do not provide a valid indication of children's level of attention and effortful control. Although previous research has provided evidence for the validity of this test, as evidenced by significant correlations with measures of intelligence, other measures of attention, and school performance [38, 39], it should be mentioned that the present study only employed five subtests of the TEA-Ch. Perhaps the administration of the full battery is necessary to really put load on children's capacity for controlling attention processes. A final, related point pertains to Epstein's [51, 52] observation that performance-based assessments are only predictive of traits, if the pertinent behavior is measured in multiple tasks for which scores are combined. The present study used five subtests of the TEA-Ch, but it may well be that this number was too small to get a valid impression of children's level of attention control.

The links between self-reported attention/effortful control and psychopathological symptoms in children were as anticipated. That is, significant negative correlations were found between scores on the ACS and ECS and levels of anxiety, depression, and aggression [26-31]. Further, the pattern of these correlations was also comparable to that 
observed in previous studies and indicates that attention control is more convincingly linked to internalizing symptoms (i.e., anxiety and depression) than to externalizing symptoms (i.e., aggression) [49]. Unfortunately, the present study did not include a pure scale for measuring inhibitory control, which seems to be the regulative trait most clearly related to externalizing symptoms $[32,53]$. The correlations between the TEA-Ch and psychopathological symptoms were small, and even non-significant after controlling for demographic variables (i.e., gender and age). On the one hand, this finding provides further support for the aforementioned notion that self-reports and performance-based measures of attention/effortful control do not assess fully similar constructs. Perhaps scales such as the ACS and ECS not only measure attention/effortful control capacity, but also tap some type of meta-cognition, namely the idea of children that they have less control over attention and other cognitive processes. Interestingly, several authors have noted that children with high levels of psychopathological symptoms report to experience less control over their emotions [54, 55], and it may well be that this is the result of children's lowered perceptions of control over various cognitive processes. On the other hand, it should be borne in mind that the TEA-Ch was administered under low-stress conditions. It may well be that children's problems with regulating negative emotions only become really manifest when their cognitive system is seriously challenged (e.g., by exposing them to a stressful situation). This implies that TEA-Ch scores would only be related to psychopathological symptoms under stressful or taxing circumstances, which is a possibility that can be tested in further research. Note that this comes close to a diathesis-stress account of psychopathology, which implies that emotional and behavioral problems only develop in vulnerable children (i.e., children with high levels of negative affectivity and/or poor regulative skills) when they are confronted with stressful or challenging events [56].

There are a number of additional findings that require some brief comment. To begin with, there were significant gender differences for symptoms of anxiety and aggression. More precisely, girls reported higher levels of anxiety symptoms, whereas boys reported higher levels of aggression. This finding is in keeping with previous research indicating that girls tend to display more internalizing problems, while boys are inclined to exhibit more externalizing symptoms [57]. Further, consistent age effects were found on indexes of attention control. In all cases, the correlations were positive: this indicates that attention control improved as children were older, which is of course in keeping with the notion that this regulative trait further develops during middle childhood [16].

Admittedly, the current study suffered from various limitations. First, the study only obtained child-reported ACS and ECS data. Although substantial parent-child correlations have been obtained for these measures [31], the inclusion of parent data would certainly have provided additional information and further strengthened our study. Second, fairly little is known on the psychometric properties of the instruments that are currently used for measuring attention and effortful control. More research in this area may yield more reliable and valid scales and tests to assess these regulative temperament factors [48]. Third, the study relied on non-clinical children who were all reasonably well-functioning, and hence displayed fairly good performance on the TEA-Ch. It may well be that more variation in TEA-Ch scores can be found in a sample of clinically referred youths [47], which of course is important when one attempts to investigate relationships with psychopathology symptoms. In spite of these shortcomings, the current data provide interesting information on the assessment of attention/effortful control, and on the relation between these regulative traits and psychopathological symptoms in youths. As noted by Hughes and Graham [58], these issues remain important points on the research agenda of clinical and developmental psychologists in the near future. 


\section{Summary}

Attention and effortful control are regulative temperament variables that are increasingly investigated in the context of child psychopathology. The present study provides additional support for the idea that lower levels of attention and effortful control are indeed associated with higher levels of anxiety, depression, and aggression. However, the results also point out that further research is necessary (a) to examine the links between attention and effortful control and child psychopathology in prospective research designs, and (b) to develop reliable and valid instruments for assessing these regulative temperament traits in children of various ages.

Open Access This article is distributed under the terms of the Creative Commons Attribution Noncommercial License which permits any noncommercial use, distribution, and reproduction in any medium, provided the original author(s) and source are credited.

\section{References}

1. Costello EJ, Mustillo S, Erkanli A, Keeler G, Angold A (2003) Prevalence and development of psychiatric disorders in childhood and adolescence. Arch Gen Psychiatry 60:837-844

2. Ford T, Goodman R, Meltzer H (2003) The British child and adolescent mental health survey 1999: the prevalence of DSM-IV disorders. J Am Acad Child Adolesc Psychiatry 42:1203-1211

3. Verhulst FC, Van der Ende J, Ferdinand RF, Kasius MC (1997) The prevalence of DSM-III-R diagnoses in a national sample of Dutch adolescents. Arch Gen Psychiatry 54:329-336

4. Achenbach TM (1991) Manual for the child behavior checklist 4-18 and 1991 profile. University of Vermont, Department of Psychiatry, Burlington, VT

5. Champion LA, Goodall G, Rutter M (1995) Behavior problems in childhood and stressors in early life. a 20-year follow-up of London school children. Psychol Med 25:231-246

6. Muris P (2006) Freud was right ... about the origins of abnormal human behavior. J Child Fam Stud $15: 1-12$

7. Essau CA, Petermann F (1999) Depressive disorders in children and adolescents: epidemiology, risk factors, and treatment. Jason Aronson, Northvale, NJ

8. Reid JB, Patterson GR, Snyder J (2002) Antisocial behavior in children and adolescents: a developmental analysis and model for intervention. American Psychological Association, Washington, DC

9. Vasey MW, Dadds MR (2001) The developmental psychopathology of anxiety. Oxford University Press, New York

10. Rothbart MK, Bates JE (2006) Temperament. In: Eisenberg N, Damon W, Lerner RM (eds) Handbook of child psychology: volume 3. Social, emotional, and personality development. Wiley, Hoboken, NJ, pp 99-166

11. Rothbart MK, Ellis LK, Posner MI (2004) Temperament and self-regulation. In: Baumeister RF, Vohs KD (eds) Handbook of self-regulation. Research, theory, and applications. Guilford, New York, pp 357-370

12. Poggi Davis E, Bruce J, Gunnar MR (2002) The anterior attention network: Associations with temperament and neuroendocrine activity in 6-year-old children. Dev Psychobiol 40:43-56

13. Kochanska G, Knaack A (2003) Effortful control as a personality characteristic of young children: antecedents, correlates, and consequences. J Pers 71:1087-1112

14. Kochanska G, Murray K, Coy KC (1997) Inhibitory control as a contributor to conscience in childhood: from toddler to early school age. Child Dev 68:263-277

15. Kochanska G, Murray K, Harlan ET (2000) Effortful control in early childhood: continuity and change, antecedents, and implications for social development. Dev Psychol 36:220-232

16. Posner MI, Rothbart MK (2000) Developing mechanisms of self-regulation. Dev Psychopathol 12: 427-441

17. Eisenberg N, Liew J, Pidada SU (2004) The longitudinal relations of regulation and emotionality to quality of Indonesian children's socioemotional functioning. Dev Psychol 40:790-804

18. Fabes RA, Eisenberg N, Jones S, Smith M, Guthrie I, Poulin R, Shepard S, Friedman J (1999) Regulation, emotionality, and preschoolers' socially competent peer interactions. Child Dev 70:432-442 
19. Eisenberg N, Cumberland A, Spinrad TL, Fabes RA, Shepard SA, Reiser M, Murphy BC, Losoya SH, Guthrie IK (2001) The relations of regulation and emotionality to children's externalizing and internalizing behavior problems. Child Dev 72:1112-1134

20. Eisenberg N, Sadovsky A, Spinrad TL, Fabes RA, Losoya SH, Valiente C, Reiser M, Cumberland A, Shepard SA (2005) Effortful control and impulsivity: concurrent relations and prediction of change. Dev Psychol 41:193-211

21. Oldehinkel AJ, Hartman C, De Winter AF, Veenstra R, Ormel J (2004) Temperament profiles associated with internalizing and externalizing problems in preadolescence. Dev Psychopathol 16: $421-440$

22. Veenstra R, Lindenberg S, Oldehinkel AJ, De Winter AF, Ormel J (2006) Temperament, environment, and antisocial behavior in a population sample of preadolescent boys and girls. Int J Behav Dev 30:422-432

23. Eisenberg N, Fabes RA, Guthrie IK, Murphy BC, Maszk P, Holmgren R, Suh K (1996) The relations of regulation and emotionality to problem behavior in elementary school children. Dev Psychopathol 8:141-162

24. Eisenberg N, Guthrie IK, Fabes RA, Shepard S, Losoya S, Murphy BC, Jones S, Poulin R, Reiser M (2000) Prediction of elementary school children's externalising problem behaviors from attention and behavioral regulation and negative emotionality. Child Dev 71:1367-1382

25. Valiente C, Eisenberg N, Smith CL, Reiser M, Fabes RA, Losoya S, Guthrie IK, Murphy BC (2003) The relations of effortful control and reactive control to children's externalizing problems: a longitudinal assessment. J Pers 71:1171-1196

26. Lonigan CJ, Phillips BM (2001) Temperamental influences on the development of anxiety disorders. In: Vasey MW, Dadds MR (eds) The developmental psychopathology of anxiety. Oxford University Press, New York, pp 60-91

27. Lonigan CJ, Vasey MW, Phillips BM, Hazen RA (2004) Temperament, anxiety, and the processing of threat-relevant stimuli. J Clin Child Adolesc Psychol 33:8-20

28. Meesters C, Muris P, Van Rooijen B (2007) Reactive and regulative temperament factors and child psychopathology: relations of neuroticism and attentional control with symptoms of anxiety and aggression. J Psychopathol Behav Assess 29:149-158

29. Muris P (2006) Unique and interactive effects of neuroticism and effortful control on psychopathological symptoms in non-clinical adolescents. Pers Individ Diff 40:1409-1419

30. Muris P, De Jong PJ, Engelen S (2004) Relationships between neuroticism, attentional control, and anxiety disorders symptoms in non-clinical children. Pers Individ Diff 37:789-797

31. Muris P, Meesters C, Rompelberg L (2007) Attention control in middle childhood: relations to psychopathological symptoms and threat perception distortions. Behav Res Ther 45:997-1010

32. Muris P, Ollendick TH (2005) The role of temperament in the etiology of child psychopathology. Clin Child Fam Psychol Rev 8:271-289

33. American Psychiatric Association (2000) Diagnostic and statistical manual of mental disorders, fourth edition-text revision (DSM-IV-TR). American Psychiatric Association, Washington, DC

34. Rothbart MK, Ahadi SA, Hershey KL, Fisher P (2001) Investigations of temperament at three to seven years: the children's behavior questionnaire. Child Dev 72:1394-1408

35. Capaldi DM, Rothbart MK (1992) Development and validation of an early adolescent temperament measure. J Early Adolesc 12:153-173

36. Derryberry D, Reed MA (2002) Anxiety-related attentional biases and their regulation by attentional control. J Abn Psychol 111:225-236

37. Murray KT, Kochanska G (2002) Effortful control: factor structure and relation to externalizing and internalizing behaviors. J Abn Child Psychol 30:503-514

38. Manly T, Anderson V, Nimmo-Smith I, Turner A, Watson P, Robertson IH (2001) The differential assessment of children's attention: the Test of Everyday Attention for Children (TEA-Ch), normative sample, and ADHD performance. J Child Psychol Psychiatry 42:1065-1081

39. Manly T, Robertson IH, Anderson V, Nimmo-Smith I (2004) The Test of Everyday Attention for Children (TEA-Ch). Harcourt Test Publishers, Lisse, The Netherlands

40. Muris P (2006) Relation between attention control and school performance in normal children. Percept Motor Skills 102:78-80

41. Chorpita BF, Yim L, Moffitt C, Umemoto LA, Francis SE (2000) Assessment of symptoms of DSM-IV anxiety and depression in children: a revised child anxiety and depression scale. Behav Res Ther 38:835-855

42. Spence SH (1998) A measure of anxiety symptoms among children. Behav Res Ther 36:545-566

43. Chorpita BF, Moffitt CE, Gray J (2005) Psychometric properties of the revised child anxiety and depression scale in a clinical sample. Behav Res Ther 43:309-322 
44. Muris P, Meesters C, Schouten E (2002) A brief questionnaire of DSM-IV defined anxiety and depression symptoms among children. Clin Psychol Psychother 9:430-442

45. Brown K, Atkins MS, Osborne ML, Milnamow M (1996) A revised teacher rating scale for reactive and proactive aggression. J Abn Child Psychol 24:473-480

46. Vincken M, Eijkelenboom A, Muris P, Meesters C (2004) Zelfcontrole: Een effectief interventie-programma voor kinderen met agressief en oppositioneel gedrag (Self-control: an effective intervention program for children with aggressive and oppositional behavior problems). Kind Adolesc Praktijk 3:17-23

47. Heaton SC, Reader SK, Preston AS, Fennell EB, Puyana OE, Gill N, Jonhson JH (2001) The Test of Everyday Attention for Children (TEA-Ch): patterns of performance in children with ADHD and clinical controls. Child Neuropsychol 7:251-264

48. Muris P, Meesters C (in press) Self-reports of reactive and regulative temperament in youths: a psychometric evaluation of the Early Adolescent Temperament Questionnaire-Revised. J Psychopathol Behav Assess

49. Muris P, Meesters C, Blijlevens P (2007) Self-reported reactive and regulative temperament in early adolescence: relations to internalizing and externalizing problem behavior and "big three" personality factors. J Adolesc 30:1035-1049

50. Muris P, Meesters C, Gobel M (2001) Reliability, validity, and normative data of the Penn State worry questionnaire in 8- to 12-year old children. J Behav Ther Exp Psychiatry 32:63-72

51. Epstein S (1979) The stability of behavior: I. On predicting most of the people much of the time. J Pers Soc Psychol 37:1097-1126

52. Epstein S (1980) The stability of behavior: II. Implications for psychological research. Am Psychologist $35: 790-806$

53. Nigg JT (2006) Temperament and developmental psychopathology. J Child Psychol Psychiatry 47:395422

54. Muris P (2002) Relationships between self-efficacy and symptoms of anxiety disorders and depression in a normal adolescent sample. Pers Individ Diff 32:337-348

55. Weems CF, Silverman WK, Rapee RM, Pina AA (2003) The role of control in childhood anxiety disorders. Cogn Ther Res 27:557-568

56. Wenar C, Kerig P (2000) Developmental psychopathology: from infancy through adolescence. McGraw-Hill, New York

57. Mash EJ, Wolfe DA (2002) Abnormal child psychology. Wadsworth, Belmont

58. Hughes C, Graham A (2002) Measuring executive functions in childhood: Problems and solutions? Child Adolesc Mental Health 7:131-142 